\title{
DOCTORAL AND MASTER'S SUPERVISION: DOES PREFERENCE FOR RESEARCH VERSUS TEACHING REALLY MAKE A DIFFERENCE?
}

\author{
C. W. Callaghan \\ Division of Management and Human Resource Management \\ School of Economic and Business Sciences \\ University of the Witwatersrand \\ Johannesburg, South Africa \\ e-mail: chris.callaghan@wits.ac.za
}

\section{ABSTRACT}

Longstanding debates exist across the literature as to potential consequences of a preference for teaching versus research for a host of academic work outcomes. Seemingly absent from the literature, however, is evidence of the effect of such a preference on academic outputs, such as master's and doctoral supervisions, and the extent such a preference and its effects are different for men or women. Applying a comprehensive purposive sampling strategy, a large South African higher institution was sampled. Structural equation models were used, with tests of path invariance to test for gender moderation, as well as further tests of such preferences as mediators of relationships between certain academic productivity variables. This study therefore seeks to investigate: (i) the potential influence of an intrinsic oppositional preference for research versus teaching on numbers of successful masters and doctoral supervisions of individual academic staff; (ii) the mediating influence of intrinsic role orientations on the relationships between successful masters and doctoral supervisions and certain of their key determinants, such as (a) years of experience as s researcher, (b) research output, (c) methodological differences (quantitative versus qualitative research preferences), and (d) work-life-balance effects; and (iii) the extent these determinants of successful postgraduate supervision are moderated by gender. Findings suggest that men with an oppositional preference for teaching report significantly higher numbers of successful master's supervisions, and those with a preference for research report significantly lower numbers of master's supervisions. At the heart of these tests of theory is the question: does a preference for research (which has been found to be associated with higher research productivity) confer an advantage in postgraduate supervision? No difference in master's supervisions was found by gender, but male supervisors were found to have significantly higher numbers of doctoral supervisions. Dependent children are found to be associated with more master's degree supervisions, but only for male academics. However, total publications output is more strongly associated with master's supervision for female academics. Academic experience is significantly associated with numbers of doctoral supervisions only for male academics. Implications of these findings are discussed, and recommendations are made.

Keywords: tertiary education, postgraduate supervision, gender 


\section{INTRODUCTION}

A dearth of postgraduate supervision skills, together with high supervisor-student ratios, reflect a longstanding and worsening crisis in postgraduate supervisory capacity faced by South African universities. Exacerbated by an aging professoriate (ASSAf 2010), this problem highlights a pressing need for research in order to better understand relationships around postgraduate supervision in this context. Much has been written on doctoral and master's degree supervision in South African universities (for example, see Albertyn, Kapp and Bitzer 2008; Mouton 2007; Waghid 2011), but whereas evidence has been found to suggest academic career progression can be constrained by an intrinsic preference for teaching over research, due to lack of recognition of teaching efforts as opposed to research under increasing pressures to "publish or perish” (Callaghan 2016), little research has investigated what effect an individual supervisor's primary intrinsic job satisfaction preferences (between teaching and research) may have on their supervision of masters and doctoral students, and particularly oppositional preferences, or a preference for research at the expense of teaching, or vice versa. According to their meta-analysis, Hattie and Marsh (1996) found satisfaction to dominate potential rewards in relation to teaching and research, suggesting the importance of intrinsic factors as a differentiator between teaching and research outcomes.

This study therefore seeks to investigate: (i) the potential influence of an intrinsic oppositional preference for research versus teaching on numbers of successful masters and doctoral supervisions of individual academic staff; (ii) the mediating influence of intrinsic role orientations on the relationships between successful masters and doctoral supervisions and certain of their key determinants, such as (a) years of experience as s researcher, (b) research output, (c) methodological differences (quantitative versus qualitative research preferences), and (d) work-life-balance effects; and (iii) the extent these determinants of successful postgraduate supervision are moderated by gender. Given substantial literature on persistent gender inequalities in the workplace in general (Bandiera and Natraj 2013; Branisa, Klasen, Ziegler, Drechsler and Jütting 2014; Baliamoune-Lutz and McGillivray 2015; Grow and Bavel 2015) and in the academic context in particular (Eboiyehi, Fayomi and Eboiyehi 2016; Morales, Avilla and Espinosa 2016; Nielsen 2016; Reilly, Jones, Vasquez and Krisjanous 2016; Zippel, Ferree and Zimmermann 2016) the potential for gender inequality in tested relationships was taken to necessitate investigation of gender moderation.

Longstanding reviews of higher education theory predict different relationships between teaching and research in universities. A seminal review by Hattie and Marsh (1996), for 
example, identifies eight different theoretical models which predict that teaching and research are related to one another in three different ways, that in turn have three different categories of consequences for academic work, where teaching and research are either synergistic - working together to improve teaching and/or research, are antagonistic - working against each other to diminish productivity, or orthogonal - having no real influence on one another.

Such theory is important, as it has implications for how academic workloads are allocated, and how academic work is designed. If synergistic, then homogeneity in workflows is to be encouraged, and individuals with an intrinsic preference for teaching should be expected to meet the demands of teaching and research more equally, as this optimal combination of these activities would be expected to yield maximum synergies. If antagonistic, then those who have the potential to be more effective and productive teachers might teach more, and vice versa, such that specialisation would be expected to yield better outcomes for students. If orthogonal, then neither strategy would necessarily be superior in terms of student outcomes. These determinations would need to be made by university management, based on evidence, such as that provided by studies like this.

Where previous research in this context has argued that preferences for teaching versus research are antagonistic in their effects on research productivity (see Callaghan 2015), what is lacking in the literature is authoritative evidence of the potential influence of oppositional preferences for teaching versus research on an individual's numbers of successful masters or doctoral supervisions. In other words, does a preference for research (which has been found to be associated with higher research productivity) confer an advantage in postgraduate supervision? This advantage would accrue to the supervisor, who is expected to have more tacit experience of research, some of which might transfer to postgraduate supervision. This might then benefit both the supervisor and student.

Or does the postgraduate supervision process itself have more in common with the interpersonal teaching process than with the more solitary research production process? This study seeks to provide a definitive answer to the question of what potential impact such oppositional preferences might have on postgraduate supervisions, and not only directly, but to the extent to which these preferences mediate the influences of certain determinants of postgraduate supervision, as well as the extent to which these relationships are gendered, given that preferences for teaching versus research have been found, themselves, be gendered. Further, this study seeks to provide a test of these bodies of theory in the context of a large South African university, a context in which constraints to postgraduate supervision impose costs to not only the student, but to the system itself. 
The literature, therefore, broadly seems to offer two alternative predictions with regard to the relationship between conflicting, or oppositional, intrinsic preferences for research versus teaching and postgraduate supervisions. On the one hand, it is possible that in the same way as an oppositional preference for teaching over research has been found to be associated with significantly lower levels of research output, it might be associated with fewer postgraduate supervisions, through the research-supervision channel related to similarities between research process and the research supervision process (which may confer an advantage to researchers in supervisions). On the other hand, if teaching preference has been found to be associated with benevolent values of caring and helping (Callaghan 2017) then it might be expected to result in higher supervision outputs, as the supervision relationship might share important caring and helping commonalities with the teaching process, through a relational channel. This potential effect is however only tested as a net association in this research. Given the burden of high inequality and resource constraints (Kruss, Haupt and Visser 2016; Booi, Vincent and Liccardo 2017) and current unrest in the South African tertiary environment related to fees protests (Hayden 2016; Luckett and Mzobe 2016; Wild 2016), constraints to postgraduate supervision are considered to pose further hurdles to student throughput in a context under increasing pressure to deliver societally important outcomes. It is considered important here to acknowledge these contextual influences, as their potential influence on the tested relationships is not clear.

Given the lack of knowledge of the potential influence of oppositional preferences for teaching versus research on numbers of successful postgraduate supervisions, this study seeks to test this direct contribution as well as the role of these preferences as mediators of the relationships between postgraduate supervision and its determinants in this context.

Having outlined the key rationales guiding the study, theory related to the relationships under study is now discussed. After this, on the basis of the literature discussed, hypotheses are derived for testing. The methods applied in the study are then outlined. Following this, the results are reported and discussed. Finally, conclusions and recommendations for further research are offered.

\section{THEORY AND HYPOTHESES}

The South African Higher Education (HE) context differs from others, and certain implications for this study based on these differences stand out. Only about a third of permanent academic staff at South African universities were found to have doctorates by 2010 (ASSAf 2010). The causes of low doctoral attainment "lie deep within the school system, where only 16 per cent 
of graduating matriculants qualify for university entrance (the exemption pass)” (ASSAf 2010, 107). Resource constraints such as those related to student funding or the funding of universities themselves are further challenges to higher education in this context (Brown and Czerniewicz 2010).

Strong relationships between production of doctoral graduates and economic growth are predicted by theory. For example, endogenous growth theory (Romer 1994) predicts increases in a nation's human capital are responsible for the development of new forms of technology and more efficient and effective means of production (ASSAf 2010,116). Constraints to higher degree throughput are particularly damaging (Aspland, Edwards, O’Leary and Ryan 1999), given the high rates of attrition and low throughput rates in the country's education system in general (ASSAf 2010).

Given that the apprenticeship model is dominant in the country, and doctoral studies are also highly context-specific, with differences between disciplines and universities making it challenging for standardisation of doctoral training (ASSAf 2010), the individual supervisor is made central to the supervision process. The tacit knowledge or experience (Polanyi 1973; Nonaka 1994) of the individual academic, which cannot easily be converted into explicit knowledge, is therefore also an important input into the supervision process. This tacit knowledge is akin to what Becker (1964) describes as "specific" human capital, which cannot simply be transferred from another context, such that research experience built up by an academic over time is not easily passed on to a student, except through tasks and experiential learning. The implication of this is that to a certain extent an academic's experience can improve the quality of postgraduate supervision over time. Similarly, if there are certain tacit skills in teaching which are common to class teaching as well as teaching postgraduate student research, then this would also be expected to be reflected in the experience of a researcher over time. For someone with an intrinsic role preference for research, higher research output is expected to contribute to more effective supervision, measured as student graduations. On the other hand, expertise in teaching might contribute to postgraduate supervision (measured as student graduations) to a similar extent, as certain of the skills and knowledge related to teaching my transfer to the postgraduate supervision process, but it is not clear which of these effects will dominate.

Postgraduate supervision itself, however, is not uniform across academic fields (Bitzer 2011), with different disciplinary norms for what is considered valid knowledge, and what should be the focus of research topics (Winberg 2009). Differences also exist in the numbers of doctoral students produced by different fields, as those from education, economic and 
management sciences as well as religious studies typically dominate, and social sciences doctoral output is five times higher than in the fields of engineering sciences, materials and technologies (ASSAf 2010). It is possible that these fields are primarily differentiated by the extent to which research uses either quantitative or quantitative methods. Preferences for quantitative versus qualitative research methods were also included as a covariate factor in testing, because there might be substantive differences in the relationships due to these effects. Using a covariate factor can remove the variance associated with the influence of such a factor. This is typical of empirical work across different fields, and is necessary to avoid obtaining spurious results.

Human capital theory (Becker 1964) predicts that investments in learning and experience contribute to productivity. Becker differentiates between specific and general human capital, the first related to tacit learning, which cannot be transferred across working contexts, and the latter to learning, which can. Postgraduate degree production is expected to be a function of expert tacit knowledge, or of years of experience as a researcher. Research supervision output, however, is expected to be a function of an individual's intrinsic task preferences, and this is expected to mediate the relationship between research productivity in terms of research outputs and supervision outputs.

Hattie and Marsh (1996) stress that despite commonalities that may exist between good teachers and researchers, there also may be more complex dimensions to this relationship such as commitment and time, which "mediate the relationship and may cause the relationship" to be negative (Hattie and Marsh 1996, 512). Certain longstanding theories have dominated discourse around the either positive or negative relationship between teaching and research. Drawing from Hattie and Marsh's (1996) seminal review of the historical literature, these seminal theories are now considered in terms of their implications for the way in which an individual's intrinsic teaching versus research orientation might mediate relationships between postgraduate supervision and its key determinants.

\section{Models predicting a negative relationship between teaching and research intrinsic orientations}

Hattie and Marsh (1996) acknowledge Moore’s (1963) concept of role conflict associated with time, energy and commitment scarcity. According to Fox (1992), investments in research are different from investments in teaching, and can cause conflict. Similarly, an intrinsic role preference for teaching will typically differ from that of research in terms of what approach is brought to postgraduate supervision. Does a "teacher" have advantages in postgraduate 
supervision versus a "researcher"? However, time "on research is positively correlated with research productivity”, yet not positively correlated with teaching quality (Hattie and Marsh 1996, 509).

From the scarcity model perspective, individuals with an intrinsic role preference for either teaching or research will be expected to allocate activities with a bias toward those aligned with role preference (Hattie and Marsh 1996). The scarcity model also suggests that time scarcity might differentiate successful postgraduate supervisions. The three requisites of South African faculty are teaching, research and community engagement. It is important to understand under what conditions one element might gain dominance.

Barbezat (2006) found the presence of children in a household to be positively and significantly associated with increased research productivity, for both men and women. This is in contrast with the notion that family-to-work spillover effects are expected to, if found, be negative rather than positive (Dilworth 2004; Dilworth and Kingsbury 2005). The differential personality model predicts that, because there are different sets of attributes associated with research versus teaching, individuals with personalities differently suited to a variety of activities or attributes, will be a better fit with either teaching or research (Hattie and Marsh 1996). According to the divergent rewards model, the conflicting roles of teaching and research are associated with different expectations and obligations, underpinned by different reward systems (Hattie and Marsh 1996). The conventional wisdom model predicts that research practice makes an individual more knowledgeable, and therefore a better teacher, all else held constant, where, because most academics have historically reported this, a positive relationship is expected (Hattie and Marsh 1996). If there is a positive relationship between these orientations, then there would perhaps be less expected variance in intrinsic role preferences as mediators of supervision determinants. The " $g$ " model predicts that underlying cognitive ability, represented as a general factor, or "g”, supports performance in both teaching and research (Hattie and Marsh 1996). According to this perspective, intrinsic role orientation would not necessarily be expected to mediate the relationships between supervision capacity and its key determinants, namely years as a researcher, research productivity, methodological preference, or family-work spillover effects. These models are summarised in Table 1.

The different enterprises, unrelated personality and the bureaucratic funding models all predict little or no relationships between teaching and research (Hattie and Marsh 1996). According to the different enterprises model, teaching is fundamentally different from research, according to the activities associated with each. The implication of this model, however, is that these activities are so different that they can "fit together" in a way so that more effort allocated 
Table 1: Theoretical predictions of relationships between teaching and research

\begin{tabular}{|c|c|}
\hline Predictions & Implications \\
\hline \multicolumn{2}{|r|}{ Negative Relationship } \\
\hline Scarcity model & $\begin{array}{l}\text { Individuals may allocate scarce resources in a way that is biased } \\
\text { toward preference for teaching versus research, which might have } \\
\text { implications for postgraduate supervision. }\end{array}$ \\
\hline Differential personality model & $\begin{array}{l}\text { Individuals with different personalities are more suited to either } \\
\text { teaching or research, which might in turn influence postgraduate } \\
\text { supervision. }\end{array}$ \\
\hline Divergent rewards model & $\begin{array}{l}\text { Different expectations and obligations of teaching and research have } \\
\text { different rewards associated with them. Rewards can be intrinsic or } \\
\text { extrinsic. Effects on postgraduate supervision are unclear. }\end{array}$ \\
\hline \multicolumn{2}{|r|}{ Positive Relationship } \\
\hline Conventional wisdom model & $\begin{array}{l}\text { Research makes an individual more knowledgeable about his or her } \\
\text { teaching practice, and therefore a better teacher. Teaching skills might } \\
\text { also generalise to supervision. }\end{array}$ \\
\hline The "g" model & $\begin{array}{l}\text { Underlying cognitive ability, as a common, or general (" } g \text { ") factor, } \\
\text { underlies performance in both teaching and research. Intrinsic } \\
\text { preferences might therefore differentiate which activity receives the } \\
\text { most time investments. }\end{array}$ \\
\hline \multicolumn{2}{|r|}{ No Expected Relationship } \\
\hline Different enterprises model & $\begin{array}{l}\text { Teaching and research are fundamentally different enterprises as they } \\
\text { entail substantially different activities. Intrinsic role preferences are } \\
\text { expected to therefore mediate determinant influences. }\end{array}$ \\
\hline Unrelated personality model & $\begin{array}{l}\text { The personality characteristics of individuals relate differently to } \\
\text { teaching and research, and do not detract from performance in either. }\end{array}$ \\
\hline Bureaucratic funding model & $\begin{array}{l}\text { Resources are more effectively invested to support comparative } \\
\text { advantage of individuals in either teaching or research. }\end{array}$ \\
\hline
\end{tabular}

Source: Hattie and Marsh (1996)

to one will not necessarily detract from performance in the other. In other words, there may be little cost or trade-off between two. If this were so, an individual's teaching versus research orientation would not necessarily have any significant mediation effect between postgraduate supervision and its determinants, over and above "natural” synergies between teaching and research, or those unrelated to individual intrinsic orientation. It is acknowledged, however, that these relationships might also be influence by the extent to which a supervisor or a student designs, or has control over important decisions in the research. Similarly, when coursework and research are combined, there might be further influences, and a supervisor might preside over both components. This study tests relationships at the net level, and it is acknowledged that further research might usefully investigate these effects in more detail. Qualitative research might be especially useful, as it may be able to build on the findings of this study and validate the causal mechanisms that underlie these tested effects. It is a limitation of statistical analysis that it cannot ascribe causality, but can only test the net effects between tested variables.

The unrelated personality model suggests that personality differences exist between researchers and teachers and that because of these differences, teaching and research are unrelated. Neither would then be expected to improve or diminish the other, and the relationship between teaching and research is then expected to be orthogonal. This theory suggests a 
differentiation between a focus on supporting others and a focus inwards, or a self-oriented aspect. It is unclear as to what this predicts for the testing of intrinsic role orientation as a mediator of supervision determinants.

The bureaucratic funding model suggests that if teaching and research are not related, then teachers and researchers should be rewarded, each for their different strengths (Hattie and Marsh 1996). This model therefore suggests that comparative advantage can be better harnessed if resources are allocated on the basis of comparative advantage. However, notwithstanding differences in financial or promotional incentives for supervision, specific incentivisation effects that might be associated with an intrinsic research or teaching preference orientation are tested in this study. It must be stressed at this point that Hattie and Marsh's seminal review is used here to sample from the eight fundamental theoretical frameworks that have across time related research to teaching. Their conclusions are regarded as probationary in this context, and this study provides a test of these theoretical predictions to the extent to which they predict relevant relationships. Hypothesis $\mathrm{A}$ is derived, that intrinsic role orientation mediates the relationships between postgraduate supervision and its key determinants, namely: experience as a researcher over time (Hypothesis A.1); total research output (Hypothesis A.2); methodological differences, or oppositional preferences for quantitative versus qualitative methods (Hypothesis A.3); and family life spillover effects, proxied by number of dependent children (Hypothesis A.4). These derived hypotheses are listed in full in Table 8, together with the results of the hypothesis testing.

Further, given evidence of continuing gender inequality in academic contexts (Eboiyehi, Fayomi and Eboiyehi 2016; Morales, Avilla and Espinosa 2016; Nielsen 2016; Reilly et al. 2016; Zippel, Ferree and Zimmermann 2016), Hypothesis B is also offered, that gender moderates the relationships between postgraduate supervisions and its determinants, namely experience as a researcher (Hypothesis B.1), total research output (Hypothesis B.2), methodological differences, or a preference for quantitative versus qualitative methods (Hypothesis B.3), family life spillover effects, or dependent children (Hypothesis B.4), and oppositional preference for research versus teaching (Hypothesis B.5). Having reviewed theory that relates intrinsic role orientation to a range of factors considered to contribute to postgraduate supervision, and having derived hypotheses for testing this body of theory, the methods applied in this study are now considered.

\section{METHODS}

The research applied an exploratory cross-sectional research design. Structural equation 
modelling was used to test theory that predicted: (i) intrinsic role mediation of certain relationships between postgraduate supervision and its predictors; and (ii) gendered moderation of these paths. These appropriateness of the methods (Schmitt and Drasgow 2002) was considered reasonable in light of the objectives of the study.

\section{Population and sample}

The sampling frame of the study consisted of all staff at a large South African higher education institution. Out of a total of about 1300 fulltime and part-time staff, 225 usable responses were received, with a response rate about 17 per cent. All staff were sampled, with respondents invited to return completed questionnaires through the internal mail system. Self-addressed envelopes were provided. Refusals were unconditionally respected. The requirements of relevance and informed consent (Anastasi 1990) were used to guide the instrument design and the sampling process. Respondents were assured of anonymity and confidentiality with regard to identifying information. A sample size calculation was performed to ensure that statistical inferences could be made. Following precedent, the significance level of five per cent, or $\alpha=$ 0.05 was chosen to indicate statistical significance (Edwards 1984).

\section{Scales and measures}

In order to capture experience and time invested in research, a compound measure of research output units was developed. A summative measure was constructed, to include numbers of (i) journal article publications indexed in Thomson Reuters's list of accredited journals (ISI journal publications), together with journals indexed by ProQuest’s IBSS list; (ii) journal article publications that are South African Department of Education accredited, but that were not ISI or IBSS indexed; (iii) conference presentations; (iv) conference proceedings; (v) book publications; and (vi) book chapters. These were asked as self-report items, in the form of ratio data (Stevens 1946).

Years as a researcher were measured as years of experience as a researcher and an academic. Questionnaire items were used to sample self-reported numbers of completed masters and doctoral supervisions. Intrinsic role orientation, or satisfaction with research versus teaching was measured by three items, broadly modelled on items from the Minnesota Satisfaction Questionnaire scales (Arvey, Bouchard, Segal and Abraham 1989). An example of one of the items is as follows: "on the whole I refer teaching to doing research”. Cronbach alpha scores for these items were found to be .886, suggesting acceptable reliability. For supplementary analysis, another two items were included, phrased as follows: "most of my 
satisfaction in my job comes from the teaching work I do", and "most of my satisfaction in my job comes from the research work I do". These two items were tested for associations with the summative oppositional preference for teaching versus research item in order to further establish the reliability of these items. The satisfaction with research item correlated positively and significantly with this item $(.570 ; \mathrm{p}<.0001)$ and the satisfaction with teaching item correlated negatively and significantly with this item $(-.754 ; \mathrm{p}<.0001)$, according to bootstrapped tests of Pearson associations with 1000 iterations.

A measure of the number of dependent children was used in order to test for potential family to work spillovers. The measure was expected to provide ratio data that met the requirements of equality, transitivity additivity and the need for a zero point (Cascio and Aguinis 2011). The item was phrased as follows: "how many dependent children do you support in your family?”

Questions related to numbers of postgraduate supervisions were phrased as follows: (i) "how many (completed) master's students have you supervised?"; and (ii) "how many (completed) PhD students have you supervised?” These measures were also expected to yield ratio data.

The gender measure consisted of an item that gave a response option of either male or female. This data was captured as binary data, with male responses scored as one and female responses scored as zero. The item measuring the extent to which an individual exhibited a preference for either quantitative or qualitative methods was phrased as follows: "do you (on average) prefer quantitative or qualitative methods in your research?” This was tested as a binary item, with quantitative methods indicated by one and qualitative methods indicated by zero in the data. The measure of home language was phrased as follows: "what language/s was/were spoken in your home when you were a child?” Given the country's history, a measure of local (African) language was included as a covariate so as to partial out effects associated with the country's specific history. Table 3 reports the descriptive statistics for these measures.

\section{Statistical testing}

A SEM was used to test paths between numbers of doctoral and masters supervisions of an individual using two models. The model testing these relationships at the masters level included: (i) years as a researcher; (ii) total research output; (iii) preference for quantitative versus qualitative methods; (iv) dependent children; (v) local language; and (vi) intrinsic role orientation, or preference for research versus teaching. At the doctoral level, the same variables were used, together with an extra variable that controlled for whether an individual reported 
having a doctorate or not. This was on account of the historical precedent of promoting staff to full professor level without doctorates, and the involvement of these staff in supervisions or cosupervisions. The inclusion of these variables was based on theory, from which this model was developed. Tests for mediation were conducted, followed by tests for gender moderation. The moderation tests used critical ratios and further tests of path invariance to verify the critical ratio estimations.

Table 2: Master's supervision fit statistics for master's and doctoral studies models

\begin{tabular}{|c|c|c|}
\hline Statistics & Masters Supervision Model & Doctoral Supervision Model \\
\hline Chi-square & $59.537^{\star \star}$ & $68.07^{\star \star}$ \\
\hline Degrees Freedom & 32 & 40 \\
\hline CMIN/DF & 1.861 & 1.702 \\
\hline $\mathrm{CFI}$ & .958 & .96 \\
\hline PCFI & .426 & .426 \\
\hline RMSEA & .062 & .056 \\
\hline $\mathrm{AIC}$ & 211.537 & 248.07 \\
\hline ECVI & .949 & 1.112 \\
\hline Hoelter & $202(p<.01) ; 175(p<.05)$ & $210(p<.01) ; 184(p<.05)$ \\
\hline Mardia Coefficient & $\begin{array}{l}\text { Male: } 18.592 \text { (critical ratio value 18.819) } \\
\text { Female: } 86.963 \text { (critical ratio value } 33.709 \text { ) }\end{array}$ & $\begin{array}{l}\text { Male:86.934 (critical ratio value } 29.887 \text { ) } \\
\text { Female: } 90.411 \text { (critical ratio value } 31.832 \text { ) }\end{array}$ \\
\hline
\end{tabular}

Model fit statistics were tested for the measurement model and the structural model together. These results are reported in Table 2. Fit values of the Comparative Fit Index (CFI) (a measure of complete covariation in the data) met the minimum values of .9 or .95, suggesting an adequate or good fit (Byrne 2010, 79) for the master's model. The test of model parsimony, namely the parsimony comparative fit index (PCFI), which takes the complexity of the model into account (Byrne 2010) is difficult to interpret, as "no threshold levels have been recommended for these indices," which are typically interpreted in relation to other goodness of fit measures (Hooper, Coughlan and Mullen 2008, 55).

The root mean square error of approximation (RMSEA) value is .062 for the masters model, which has been considered reasonable fit (Brown and Cudek 1993). Byrne (2010, 81) argues that the RMSEA measure is particularly important, as it is sensitive to model misspecification, and “commonly used interpretative guidelines would appear to yield appropriate conclusions regarding model quality”. The doctoral supervision model value is .056, which suggests a slightly better fit than the master's supervision model. In terms of parsimony in model fit, taking into account numbers of parameters, the Akaike's Information Criterion (AIC) value for the master's model is lowest for the default model versus the saturated and independence models, suggesting better fit (Byrne 2010, 82). 
The Expected Cross-Validation Index (ECVI) value for the model is also less than that of the saturated and independence models, also suggesting reasonable fit for the master's model. ECVI can only be assessed comparatively against these other two models, because it can take any value, and there is therefore "no determined appropriate range of values" that can be used for comparisons (Byrne 2010, 82). For both models, the HOELTER .01 value is above 200, which represents adequate fit, but the value for the .05 level of significance is 175 . Kenny $(2015,1)$ argues that values of less than 75 "indicate very poor model fit". On the basis of these statistics, the model was taken to represent, on balance, a reasonable fit with the data. Having outlined the methods applied in the study, the results are now reported and discussed.

\section{RESULTS}

In terms of univariate results, Table 3 reports the descriptive statistics for the tested variables. About 47 per cent of the sample were male. The mean age of respondents is 40.67 years. Mean experience as a researcher is 10.2 years. On average, an academic was found to have supervised just over six master's students and just under one doctoral student over the course of his or her career. The average academic was found to have a total of just less than 22 academic units of output. In the following sections, the individual hypotheses are used as headings under which the results are reported and discussed.

Table 3: Descriptive statistics

\begin{tabular}{|l|l|l|l|l|}
\hline Variable & Mean/ Proportion & Standard Deviation & Skewness & Kurtosis \\
\hline Satisfaction with teaching & 4.25 & 1.58 & -.128 & -.561 \\
\hline Satisfaction with research & 4.87 & 1.55 & -.586 & -.013 \\
\hline Satisfaction with administration & 2.23 & 1.53 & 1.16 & .515 \\
\hline Research versus teaching & 12.44 & 4.646 & -.223 & -.253 \\
\hline Age & 40.67 & 10.56 & .420 & -.337 \\
\hline Gender (male=1)* & $47 \%$ & - & - & - \\
\hline Years of experience as a researcher & 10.2 & 8.84 & 1.598 & 2.789 \\
\hline Master's supervised & 6.19 & 9.554 & 2.561 & 8.106 \\
\hline Doctorates supervised & .95 & 2.731 & 5.107 & 35.605 \\
\hline Total units research output & 21.97 & 35.67 & 3.233 & 11.95 \\
\hline $\begin{array}{l}\text { Preference for quantitative versus } \\
\text { qualitative methods }\end{array}$ & $45.6 \%$ & - & - & - \\
\hline Dependent children & 1.09 & 1.28 & 1.33 & .324 \\
\hline Local language* & $24.4 \%$ & - & - & - \\
\hline *Proportion & \multicolumn{3}{|l}{} \\
\hline
\end{tabular}

\section{Hypothesis A: Intrinsic role orientation mediates the relationships between postgraduate supervision and its key determinants}

The results of the mediator testing are reported in Tables 4 and 5, which relate to master's 
supervisions and doctoral supervisions, respectively. Results are differentiated by gender in these tables. In each case, the null-hypotheses A.1, A.2, A.3, and A.4 were not rejected. For both male and female cohorts, preference for research versus teaching was therefore not found to mediate the following relationships between doctoral or master's supervisions and each of (i) experience, or years as a researcher; (ii) total research output; (iii) preference for quantitative versus qualitative research; and (iv) numbers of dependent children. These results suggest that preference for research versus teaching does not act as a channel path through which these determinants influence numbers of supervisions. An oppositional preference for either research or teaching is therefore not a differentiator for successful supervisions, whether for men or women, in this context. The scarcity, differential personality and divergent rewards models, which predict negative relationships between teaching and research (Hattie and Marsh 1996), are not supported, to the extent that they might predict that these negative relationships might influence the relationships between postgraduate supervision and its determinants.

Table 4: Mediator testing for master's supervisions

\begin{tabular}{|l|l|l|l|}
\hline Relationship & $\begin{array}{l}\text { Direct without Mediator } \\
\text { Male/Female }\end{array}$ & $\begin{array}{l}\text { Direct with Mediator } \\
\text { Male/Female }\end{array}$ & Indirect Male/Female \\
\hline $\begin{array}{l}\text { Years as a Researcher } \\
\text { Research Versus } \\
\text { Teaching Master } \\
\text { Supervisions }\end{array}$ & $.513(.002) / .277(.028)$ & $.494(.002) / .278(.033)$ & $\begin{array}{l}\text { Not significant: No } \\
\text { mediation }\end{array}$ \\
\hline $\begin{array}{l}\text { Preference Quant } \\
\text { Research Versus } \\
\text { Teaching Master } \\
\text { Supervisions }\end{array}$ & $.037(.64) /-.098(.10)$ & $.053(.50) /-.10(.115)$ & $\begin{array}{l}\text { Not significant: No } \\
\text { mediation }\end{array}$ \\
\hline $\begin{array}{l}\text { Dependent Children } \\
\text { Research Versus } \\
\text { Teaching Master } \\
\text { Supervisions }\end{array}$ & $.283(.002) /-.034(.58)$ & $.285(.003) /-.031(.630)$ & $\begin{array}{l}\text { Not significant: No } \\
\text { mediation }\end{array}$ \\
\hline $\begin{array}{l}\text { Local Language } \\
\text { Research Versus } \\
\text { Teaching Master } \\
\text { Supervisions }\end{array}$ & $-.222(.002) /-.096(.013)$ & $-.197(.008) /-.096(.011)$ & $\begin{array}{l}\text { Significant at within 10\% } \\
\text { level of significance only } \\
\text { for male sample. No } \\
\text { mediation effect found. }\end{array}$ \\
\hline $\begin{array}{l}\text { Total Units Research } \\
\text { Versus Teaching Master } \\
\text { Supervisions }\end{array}$ & $-.076(.562) / .194(.195)$ & $-.036(.756) / .183(.230)$ & $\begin{array}{l}\text { Although for male } \\
\text { sample indirect effect is } \\
\text { significant, direct effect is } \\
\text { not, and therefore no } \\
\text { mediation effect is found. }\end{array}$ \\
\hline
\end{tabular}

Notes: Standardised Effects with Bootstrapped significance $p$ values in parentheses

The models predicting synergistic relationships between a preference for research and teaching, namely the conventional wisdom model and the "g" model (Hattie and Marsh 1996) are therefore supported by these results, suggesting that in this context, the influence of intrinsic role preference does not differentiate the impact of postgraduate supervision determinants. These finding also support the predictions of the different enterprises, unrelated personality, and bureaucratic funding models (Hattie and Marsh 1996). These findings are considered important, in that they provide evidence to support the notion that unlike the relationships 
between research versus teaching and research output, where intrinsic role orientation is a primary differentiator of research performance, postgraduate supervision is not related to the extent to which an individual has a preference for teaching or research in this context. Preference for teaching versus research (the inverse of research versus teaching) was found to be negatively and significantly associated with Department of Higher Education and Training accredited journal article publications (rho=-.168; $\mathrm{p}<.0001$ ), ISI or IBSS indexed journal publications (rho=-.300; $\mathrm{p}<.0001$ ), conference proceedings publications (rho=-.178; $\mathrm{p}<.0001$ ), conference presentations (rho=-.254; $\mathrm{p}<.0001$ ), and book chapter (rho=-.180; $\mathrm{p}<.007$ ), as well as book (rho=-.180; $\mathrm{p}<.007)$ publications.

Table 5: Mediator testing for doctoral supervisions

\begin{tabular}{|l|l|l|l|}
\hline Relationship & $\begin{array}{l}\text { Direct without Mediator } \\
\text { Male/Female }\end{array}$ & $\begin{array}{l}\text { Direct with Mediator } \\
\text { Male/Female }\end{array}$ & Indirect Male/Female \\
\hline $\begin{array}{l}\text { Years as a Researcher } \\
\text { Research versus } \\
\text { Teaching PhD } \\
\text { Supervisions }\end{array}$ & $.279(.081) / .079(.337)$ & $.262(.083) / .084(.33)$ & $\begin{array}{l}\text { Not Significant No } \\
\text { Mediation }\end{array}$ \\
\hline $\begin{array}{l}\text { NA Research versus } \\
\text { Teaching PhD } \\
\text { Supervisions }\end{array}$ & $-.090(.332) /-.015(.784)$ & $-.103(.186) /-.01(.893)$ & $\begin{array}{l}\text { Not Significant No } \\
\text { Mediation }\end{array}$ \\
\hline $\begin{array}{l}\text { Preference Quant } \\
\text { Research versus } \\
\text { Teaching PhD } \\
\text { Supervisions }\end{array}$ & $.101(.304) /-.037(.506)$ & $.108(.279) /-.041(.537)$ & Not Significant No \\
\hline $\begin{array}{l}\text { Dependent Children } \\
\text { Research versus } \\
\text { Teaching PhD } \\
\text { Supervisions }\end{array}$ & $.157(.246) / .085(.501)$ & $.158(.248) / .09(.466)$ & Mediation \\
\hline $\begin{array}{l}\text { Local Language } \\
\text { Research versus } \\
\text { Teaching PhD } \\
\text { Supervisions }\end{array}$ & $-184(.012) /-.06(.106)$ & $-.170(.031) /-.061(.104)$ & Mediation \\
\hline $\begin{array}{l}\text { Total Units Research } \\
\text { versus Teaching PhD } \\
\text { Supervisions }\end{array}$ & $.093(.581) / .219(.156)$ & $.117(.453) / .205(.168)$ & $\begin{array}{l}\text { Not Significant No } \\
\text { Mediation }\end{array}$ \\
\hline
\end{tabular}

Notes: Standardised Effects with Bootstrapped significance $p$ values in parentheses $C$

\section{Hypothesis B: Gender moderates the relationships between postgraduate supervision and its key antecedents (determinants together with intrinsic role orientation)}

Men were found to have significantly higher levels of total oppositional preference for research over teaching ( $\mathrm{t}=-2.948 ; \mathrm{p}<.0035)$, and higher non-oppositional preference for research $(\mathrm{t}=-$ 1.963; $\mathrm{p}<.05$ ), but women were found to report a significantly higher non-oppositional preference for teaching $(\mathrm{t}=3.316 ; \mathrm{p}<.001)$. However, in terms of a non-oppositional preference for administration, there was no significant differences in t-test significance between the sexes $(\mathrm{t}=-1.356 ; \mathrm{p}<.176)$. 
According to t-test results, numbers of successful masters supervisions were not found to differ by gender ( $\mathrm{t}=.4877 ; \mathrm{p}<.6263)$. Tests of differences in structural paths using critical ratios (Table 6) found significant gender differences in four of the tested paths.

Total units of academic output were found to be more strongly associated with a preference for research over teaching for women $(p<.10)$. This association suggests that the relationship between oppositional preferences for research over teaching is significantly associated with higher research output for women, to a greater extent than men. It is possible that this preference differentiates women more strongly than men, given that on average, women report a higher preference for teaching as well as an oppositional preference for teaching over research. This result reflects the contribution of total research outputs to successful master's supervisions, which is negative and significant within the ten per cent level for women, but not for men. This suggests that women with more of a research focus might choose to supervise fewer master's students.

Table 6: Critical ratio differences between male and female master's sample paths

\begin{tabular}{|c|c|c|c|c|c|c|c|}
\hline & & & \multicolumn{2}{|c|}{ Male } & \multicolumn{2}{|c|}{ Female } & \multirow[b]{2}{*}{ z-score } \\
\hline & & & Estimate & $\mathbf{P}$ & Estimate & $\mathbf{P}$ & \\
\hline $\begin{array}{l}\text { Research Versus } \\
\text { Teaching }\end{array}$ & $<---$ & $\begin{array}{l}\text { Years as a } \\
\text { researcher }\end{array}$ & -0.011 & 0.408 & -0.001 & 0.970 & 0.483 \\
\hline $\begin{array}{l}\text { Research Versus } \\
\text { Teaching }\end{array}$ & $<<--$ & $\begin{array}{l}\text { Total research } \\
\text { outputs }\end{array}$ & 0.005 & 0.079 & 0.019 & 0.004 & $1.94^{*}$ \\
\hline $\begin{array}{l}\text { Research Versus } \\
\text { Teaching }\end{array}$ & $<---$ & Preference Quant 1 & 0.213 & 0.298 & 0.112 & 0.555 & -0.362 \\
\hline $\begin{array}{l}\text { Research Versus } \\
\text { Teaching }\end{array}$ & $<---$ & Dependent children & 0.007 & 0.909 & -0.117 & 0.262 & -1.018 \\
\hline $\begin{array}{l}\text { Research Versus } \\
\text { Teaching }\end{array}$ & $<---$ & Local Language & 0.310 & 0.121 & 0.000 & 0.999 & -0.840 \\
\hline Master's supervised & $<---$ & $\begin{array}{l}\text { Years as a } \\
\text { researcher }\end{array}$ & 0.449 & 0.000 & 0.364 & 0.004 & -0.531 \\
\hline Master's supervised & $<---$ & Preference Quant 1 & 1.064 & 0.483 & -1.689 & 0.228 & -1.333 \\
\hline Master's supervised & $<---$ & Dependent children & 1.760 & 0.000 & -0.286 & 0.712 & $-2.254^{\star \star}$ \\
\hline Master's supervised & $<---$ & Local Language & -3.827 & 0.009 & -2.625 & 0.252 & 0.442 \\
\hline Master's supervised & $<---$ & $\begin{array}{l}\text { Total research } \\
\text { outputs }\end{array}$ & -0.007 & 0.744 & 0.091 & 0.064 & $1.828^{*}$ \\
\hline $\begin{array}{l}\text { Research versus } \\
\text { Teaching } 2\end{array}$ & $<<--$ & $\begin{array}{l}\text { Research versus } \\
\text { Teaching }\end{array}$ & 1.641 & 0.000 & 1.308 & 0.000 & -1.228 \\
\hline $\begin{array}{l}\text { Research versus } \\
\text { Teaching } 3\end{array}$ & $<---$ & $\begin{array}{l}\text { Research versus } \\
\text { Teaching }\end{array}$ & 1.312 & 0.000 & 1.286 & 0.000 & -0.117 \\
\hline Master's supervised & $<<--$ & $\begin{array}{l}\text { Research versus } \\
\text { Teaching }\end{array}$ & -1.553 & 0.028 & 0.274 & 0.705 & $1.805^{*}$ \\
\hline
\end{tabular}

For the contribution of a preference for research over teaching to master's supervisions (Table 6), however, the relationship between oppositional preference and numbers of successful master's supervisions is found to be negative for men, with no significant association for women. It is possible that men who have a higher oppositional preference for teaching might 
have higher numbers of successful master's supervisions. The master's supervision process might share certain task similarities with the teaching process itself. It is possible that for men who have a preference for teaching, the conventional wisdom model may offer a useful explanation for their higher numbers of supervisions; according to this model, a teaching preference might lead to improved knowledge of teaching, which can be usefully applied to masters supervisions. Another plausible explanation for this is that men who prefer research might choose to take fewer master's students, so as to focus instead on doctoral students, or on research itself. The scarcity model suggests that individuals will allocate resources (including time) on the basis of their preference for research (Hattie and Marsh 1996), which might be at the expense of masters supervision. Similarly, the differential personality model might also predict this relationship for those with an oppositional preference for research. The divergent rewards model suggests that different expectations and rewards associated with different tasks can shape behaviour (Hattie and Marsh 1996), and if promotional criteria are better served by adding marginal numbers of research publications at the expense of masters supervisions, then this result would also be expected. Notably, these differences are not present for doctoral supervisions, which might weigh more heavily in promotional and performance criteria than master's supervisions.

It is possible that women with more research output and men with a preference for research versus teaching both supervise fewer master's students (the alternative, that they are less successful at supervisions, and hence have fewer supervisions, is not considered as likely an explanation).

Numbers of dependent children are found to be positively related to numbers of successful masters supervisions for men only. This might suggest support for the scarcity model (Hattie and Marsh 1996), where if the burden of family-related time investments falls unequally on women in this context. In line with previous research which has found a positive relationship between the presence of dependent children and research output (Barbezat 2006), the same is found here, but in contrast to these findings, it is found only for men. It is unlikely that women would be less motivated by the presence of dependent children, so these results suggest that while men and women might both be motivated by family responsibilities, unequal family workloads experienced by women might make then relatively more vulnerable negative familyto-work spillover effects (Dilworth 2004; Dilworth and Kingsbury 2005), which cancel out the motivational effect through the time scarcity channel.

On account of these results, it is recommended that university administration ensure onsite day care facilities, and other support for childcare in office hours, as a lack of such support 
might be related to the productivity of women in this context.

Table 7: Critical ratio differences between male and female doctoral sample paths

\begin{tabular}{|c|c|c|c|c|c|c|c|}
\hline & & & \multicolumn{2}{|c|}{ Male } & \multicolumn{2}{|c|}{ Female } & \multirow[b]{2}{*}{ z-stat } \\
\hline & & & Estimate & $\mathbf{P}$ & Estimate & $\mathbf{P}$ & \\
\hline $\begin{array}{l}\text { Research versus } \\
\text { Teaching }\end{array}$ & $<---$ & $\begin{array}{l}\text { Years as a } \\
\text { researcher }\end{array}$ & -0.015 & 0.270 & -0.013 & 0.452 & 0.108 \\
\hline $\begin{array}{l}\text { Research versus } \\
\text { Teaching }\end{array}$ & $<---$ & Total units & 0.005 & 0.093 & 0.013 & 0.054 & 1.096 \\
\hline $\begin{array}{l}\text { Research versus } \\
\text { Teaching }\end{array}$ & $<---$ & Preference Quant 1 & 0.184 & 0.359 & 0.116 & 0.527 & -0.249 \\
\hline $\begin{array}{l}\text { Research versus } \\
\text { Teaching }\end{array}$ & $<---$ & Dependent children & 0.005 & 0.938 & -0.086 & 0.396 & -0.763 \\
\hline $\begin{array}{l}\text { Research versus } \\
\text { Teaching }\end{array}$ & $<---$ & Local language & 0.352 & 0.080 & 0.059 & 0.844 & -0.809 \\
\hline $\begin{array}{l}\text { Research versus } \\
\text { Teaching }\end{array}$ & $<---$ & $\mathrm{Mr} / \mathrm{Ms}$ & -0.197 & 0.195 & -0.778 & 0.003 & $-1.909^{*}$ \\
\hline PhD supervised & $<---$ & $\begin{array}{l}\text { Years as a } \\
\text { researcher }\end{array}$ & 0.099 & 0.038 & 0.013 & 0.416 & $-1.7^{*}$ \\
\hline PhD supervised & $<---$ & PreferenceQuant1 & 0.962 & 0.169 & -0.086 & 0.621 & -1.453 \\
\hline PhD supervised & $<---$ & Dependent children & 0.398 & 0.070 & 0.101 & 0.293 & -1.234 \\
\hline PhD supervised & $<---$ & Local language & -1.124 & 0.102 & -0.202 & 0.479 & 1.239 \\
\hline PhD supervised & $<---$ & Total units & 0.009 & 0.380 & 0.012 & 0.051 & 0.306 \\
\hline $\begin{array}{l}\text { Research versus } \\
\text { Teaching } 2\end{array}$ & $<---$ & $\begin{array}{l}\text { Research versus } \\
\text { Teaching }\end{array}$ & 1.646 & 0.000 & 1.301 & 0.000 & -1.269 \\
\hline $\begin{array}{l}\text { Research versus } \\
\text { Teaching } 3\end{array}$ & <--- & $\begin{array}{l}\text { Research versus } \\
\text { Teaching }\end{array}$ & 1.315 & 0.000 & 1.279 & 0.000 & -0.162 \\
\hline PhD supervised & $<<---$ & $\begin{array}{l}\text { Research versus } \\
\text { Teaching }\end{array}$ & -0.349 & 0.280 & 0.066 & 0.478 & 1.235 \\
\hline PhD supervised & $<---$ & $\mathrm{Mr} / \mathrm{Ms}$ & -0.583 & 0.267 & -0.491 & 0.052 & 0.158 \\
\hline
\end{tabular}

Notes: ${ }^{\star \star \star} p$-value $<0.01 ; * \star p$-value $<0.05 ;$ * $p$-value $<0.10$

In terms of successful doctoral supervisions (Table 7), men are found to have significantly higher numbers of doctoral supervisions according to t-test results $(\mathrm{t}=-2.959 ; \mathrm{p}<.0037)$. According to tests of differences in structural paths using critical ratios, years as a researcher are found to be significantly associated with higher numbers of successful doctoral supervisions for men, but not for women. It is possible, however, that women may invest more in masters supervision, thus creating enabling conditions for men. This result suggests that, unlike at the master's level, at the doctoral level years of experience do not contribute equally to successful doctoral supervisions for men and women. This is the only path found to differ significantly between the sexes. An oppositional preference for research versus teaching is not found to be significantly related to doctoral supervisions, for women or for men. This suggests support for the different enterprises or unrelated personality models, in that neither research nor teaching offers an advantage in doctoral supervisions. Table 8 offers a summary of the results of the hypothesis testing. 
Table 8: Summary of hypothesis testing

\begin{tabular}{|c|c|}
\hline \multicolumn{2}{|l|}{ Hypotheses relating to Mediation } \\
\hline $\begin{array}{l}\text { Hypothesis A: Oppositional preference for teaching versus research } \\
\text { mediates the relationships between postgraduate supervision and its key } \\
\text { determinants. }\end{array}$ & Null not rejected \\
\hline $\begin{array}{l}\text { Hypothesis A.1. Oppositional preference for teaching versus research } \\
\text { mediates the relationship between master's/doctoral studies supervision } \\
\text { and experience. }\end{array}$ & Null not rejected \\
\hline $\begin{array}{l}\text { Hypothesis A.2. Oppositional preference for teaching versus research } \\
\text { mediates the relationship between master's/doctoral studies supervisions } \\
\text { and total research output. }\end{array}$ & Null not rejected \\
\hline $\begin{array}{l}\text { Hypothesis A.3. Oppositional preference for teaching versus research } \\
\text { mediates the relationship between master's/doctoral studies supervisions } \\
\text { and methodological preferences. }\end{array}$ & Null not rejected \\
\hline $\begin{array}{l}\text { Hypothesis A.4. Oppositional preference for teaching versus research } \\
\text { mediates the relationship between master's/doctoral studies supervisions } \\
\text { and dependent children. }\end{array}$ & Null not rejected \\
\hline \multicolumn{2}{|l|}{ Hypotheses relating to Moderation } \\
\hline $\begin{array}{l}\text { Hypothesis A: Gender orientation moderates the relationships between } \\
\text { postgraduate supervision and its key determinants. }\end{array}$ & Null rejected \\
\hline $\begin{array}{l}\text { Hypothesis A.1. Gender moderates the relationship between } \\
\text { master's/doctoral studies supervision and experience. }\end{array}$ & $\begin{array}{l}\text { Null rejected for masters and } \\
\text { doctoral supervisions. }\end{array}$ \\
\hline $\begin{array}{l}\text { Hypothesis A.2. Gender moderates the relationship between } \\
\text { master's/doctoral studies supervisions and total research output. }\end{array}$ & $\begin{array}{l}\text { Null not rejected for masters } \\
\text { supervisions. Null rejected for } \\
\text { doctoral supervisions. }\end{array}$ \\
\hline $\begin{array}{l}\text { Hypothesis A.3. Gender moderates the relationship between } \\
\text { master's/doctoral studies supervisions and methodological preferences. }\end{array}$ & Null not rejected \\
\hline $\begin{array}{l}\text { Hypothesis A.4. Gender moderates the relationship between } \\
\text { master's/doctoral studies supervisions and dependent children. }\end{array}$ & Null not rejected \\
\hline $\begin{array}{l}\text { Hypothesis A.5. Gender moderates the relationship between } \\
\text { master's/doctoral studies supervisions and oppositional preferences for } \\
\text { research versus teaching. }\end{array}$ & $\begin{array}{l}\text { Null rejected for masters } \\
\text { supervisions but null not } \\
\text { rejected for doctoral } \\
\text { supervisions. }\end{array}$ \\
\hline
\end{tabular}

The higher successful supervisions of men who reported an oppositional preference for teaching versus research seem to only hold for master's supervisions. It is possible that at the master's level, a teaching preference offers an advantage for male supervisors, but that this does not extend to doctoral supervisions. It must be noted, however, that the extent to which teaching and research are built into masters programmes were not explicitly considered in this study, and it is hoped that future research will explore these issues further. Men with more dependent children are found to have more successful doctoral supervisions, but this association is significant at within the ten per cent level of significance. This association is not significant for women. Women, however, with higher research output, or higher units of research output, are found to have more successful doctoral supervisions, at the threshold level of significance $(\mathrm{p}<.051)$. This relationship is not significant at all for men, but does not test significantly differently according to the critical ratio estimation process. This result, nevertheless, suggests that women produce more doctoral supervisions through the research output channel, and men through years of experience. Given historical inequality in this context, it is possible that these differences reflect historical context. 


\section{CONCLUSIONS}

The objective of this study was to test theory that predicted relationships around the influence of oppositional preferences for research over teaching on numbers of successful postgraduate supervisions of academic staff in a large South African university. No successful mediator effects were found for the role of oppositional preferences for research versus teaching as a channel for determinants of numbers of successful postgraduate supervisions. Men were found to have significantly higher levels of oppositional preferences for research versus teaching, as well as higher non-oppositional preference for research, and vice versa for women. Numbers of successful masters supervisions, however, were not found to differ by gender, although men were found to have more doctoral supervisions. Dependent children were found to be positively associated with numbers of successful masters supervisions for men but not for women. This relationship was also found for doctoral supervisions, although in a weaker form. On the basis of the literature, it was broadly concluded that while more dependent children might provide a motivating effect for both men and women, unequal childcare responsibilities might place a disproportionate burden on women that might disintermediate the positive effect of dependent children on postgraduate supervisions. It was suggested that this effect might work though constraints to time, as argued by the scarcity model. Relatedly, years as a researcher were found to significantly contribute to doctoral supervisions only for men, but total research output was found to contribute to master's supervisions more strongly for women. It was concluded that it is possible that men who produce more research output might be choosing to supervise fewer master's students. This finding found support in another finding, that men with an oppositional preference for teaching over research were found to have significantly higher numbers of master's supervisions. Further research is recommended, especially research that can apply qualitative methods so as to derive knowledge of the causal mechanisms that underlie the findings reported here.

\section{REFERENCES}

Academy of Science of South Africa. 2010. The PHD Study. An evidence-based study on how to meet the demands for high-level skills in an emerging economy. Academy of Science of South Africa. September. http://www.assaf.co.za/wp-content/uploads/2010/11/40696-Boldesign-PHD-small. pdf (Accessed 13 June 2013).

Albertyn, R. M., C. A. Kapp and E. M. Bitzer. 2008. Profiling exiting postgraduate students' performance and experiences. South African Journal of Higher Education 22(4): 749-772.

Anastasi, A. 1990. Psychological testing. $6^{\text {th }}$ Edition. New York: Macmillan.

Arvey, R. D., T. J. Bouchard, N. L. Segal and L. M. Abraham. 1989. Job satisfaction: Environmental and genetic components. Journal of Applied Psychology 74(2): 187-192.

Aspland, T., H. Edwards, J. O’Leary and Y. Ryan. 1999. Tracking new directions in the evaluation of 
postgraduate supervision. Innovative Higher Education 24(2): 127-147.

ASSAf see Academy of Science of South Africa.

Baliamoune-Lutz, M. and M. McGillivray. 2015. The impact of gender inequality in education on income in Africa and the Middle East. Economic Modelling 47: 1-11.

Bandiera, O. and A. Natraj. 2013. Does gender inequality hinder development and economic growth? Evidence and policy implications. The World Bank Research Observer 28(1): 2-21.

Barbezat, D. A. 2006. Gender differences in research patterns among PhD economists. Journal of Economic Education 37(3): 359-375.

Becker, G. S. 1964. Human capital. Chicago: University of Chicago Press.

Bitzer, E. M. 2011. Knowledge with wisdom is postgraduate studies and supervision: Epistemological and institutional concerns and challenges. South African Journal of Higher Education 25(5): 855874.

Booi, M., L. Vincent and S. Liccardo. 2017. Counting on demographic equity to transform institutional cultures at historically white South African universities? Higher Education Research \& Development 36(3): 498-510.

Branisa, B., S. Klasen, M. Ziegler, D. Drechsler and J. Jütting. 2014. The institutional basis of gender inequality: The Social Institutions and Gender Index (SIGI). Feminist Economics 20(2): 29-64.

Brown, C. and L. Czerniewicz. 2010. Debunking the "digital native”: Beyond digital apartheid, towards digital democracy. Journal of Computer Assisted Learning 26: 357-369.

Browne, M. W. and R. Cudeck. 1993. Alternative ways of assessing model fit. In Testing structural equation models, ed. K. A. Bollen and J. S. Long, 136-162. Newbury Park, CA: Sage.

Byrne, B. M. 2010. Structural equation modeling with Amos: Basic concepts, applications, and programming. $2^{\text {nd }}$ Edition. New York, NY: Taylor and Francis Group.

Callaghan, C. W. 2015. Designation differences and academic career progression. Acta Commercii 15(1): $1-12$.

Callaghan, C. W. 2016. "Publish or perish": Family life and academic research productivity. South African Journal of Human Resources Management 14(1): 1-9.

Callaghan, C. W. 2017. Motivational values and gendered research performance. Acta Commercii 17(2): $1-12$.

Cascio, W. F. and H. Aguinis. 2011. Applied psychology in human resource management. New Jersey: Pearson.

Dilworth, J. E. L. 2004. Predictors of negative spillover from family to work. Journal of Family Issues 25: 241-261.

Dilworth, J. E. and N. Kingsbury. 2005. Home-to-job spillover for Generation X, boomers, and matures: A comparison. Journal of Family and Economic Issues 26(2): 267-281.

Eboiyehi, C. O., I. Fayomi and F. A. Eboiyehi. 2016. From exclusion to discrimination: Gender inequality in the senior management of Nigerian universities. Issues in Educational Research 26(2): 182-205.

Edwards, A. L. 1984. An Introduction to linear regression and correlation. $2^{\text {nd }}$ Edition. New York: W. H. Freeman and Company.

Fox, M. F. 1992. Research, teaching, and publication productivity: Mutuality versus competition in academia. Sociology of Education 65: 293-305.

Grow, A. and J. V. Van Bavel. 2015. Assortative mating and the reversal of gender inequality in education in Europe: An agent-based model. PloS one 10.6: e0127806.

Hattie, J. and H. W. Marsh. 1996. The relationship between research and teaching: A meta-analysis. Review of Educational Research 66(4): 507-542.

Hayden, E. C. 2016. South African universities awash in political turmoil. Nature 535(7611): 207-208. 
Hooper, D., J. Coughlan and M. Mullen. 2008. Structural equation modelling: Guidelines for determining model fit. Electronic Journal of Business Research Methods 6(1): 53-60.

Kenny, D. A. 2015. Measuring model fit. http://davidakenny.net/cm/fit.htm (Accessed 28 February 2017).

Kruss, G., G. Haupt and M. Visser. 2016. "Luring the academic soul”: Promoting academic engagement in South African universities. Higher Education Research \& Development 35(4): 755-771.

Luckett, T. and D. Mzobe. 2016. \#OutsourcingMustFall: The role of workers in the 2015 protest wave at South African universities. Global Labour Journal 7(1): 1.

Moore, W. E. 1963. Man, time and society. New York: Wiley.

Morales, M. P. E., R. A. Avilla and A. A. Espinosa. 2016. Does gender inequality influence interest in pursuing a career in science or mathematics teaching? Issues in Educational Research 26(1): 6581.

Mouton, J. 2007. Post-graduate studies in South Africa: Myths, misconceptions and challenges. South African Journal of Higher Education 21(8): 1078-1090.

Nielsen, M. W. 2016. Gender inequality and research performance: Moving beyond individualmeritocratic explanations of academic advancement. Studies in Higher Education 41(11): 20442060.

Nonaka, I. 1994. A dynamic theory of organizational knowledge creation. Organization Science 5(1): $14-37$.

Polanyi, M. 1973. Personal knowledge: Toward a post-critical philosophy. London: Routledge \& Kegan Paul.

Reilly, A., D. Jones, C. Rey Vasquez and J. Krisjanous. 2016. Confronting gender inequality in a business school. Higher Education Research \& Development 35(5): 1025-1038.

Romer, P. M. 1994. The origins of endogenous growth. Journal of Economic Perspectives 8(1): 3-22.

Schmitt, N. and F. Drasgow. 2002. Applied problems and methods of analysis. In Measuring and analysing behavior in organisations: Advances in measurement and data analysis, ed. F. Drasgow and N. Schmitt. San Francisco: Jossey-Bass.

Stevens, S. S. 1946. On the theory of scales of measurement. Science 103(2684): 677-680.

Waghid, Y. 2011. Initiating debate. On Cavellian scepticism and postgraduate student supervision. South African Journal of Higher Education 25(3): 393-396.

Wild, S. 2016. Violence escalates at South African universities. Nature 538(7626): 440-441.

Winberg, C. 2009. Engineers are from Mars and educators are from Venus: Research supervision in engineering and educational collaboration. South African Journal of Higher Education 23(1): 205-217.

Zippel, K., M. M. Ferree and K. Zimmermann. 2016. Gender equality in German universities: Vernacularising the battle for the best brains. Gender and Education 28(7): 867-885. 